\title{
CONF-98040Z-- \\ EXAMINATION OF RADIOACTIVE DECAY METHODOLOGY IN THE HASCAL CODE
}

$\log$ No. 48

\author{
R. S. Steffler \\ Department of Nuclear Engineering \\ Texas A\&M University \\ College Station, Texas 77843-3133
}

J. C. Ryman, J. C. Gehin, B. A. Worley

Oak Ridge National Laboratory*

P.O. Box 2008, MS-6363

Oak Ridge, Tennessee 37831-6363

\section{RECEIVED}

FFR 251998

OSTI

\section{"The submitted manuscript has been authored by a contractor of the U.S. Government under contract DE-AC05- 96OR22464. Accordingly, the U.S. Government retains a nonexclusive, royalty- free license to publish or reproduce the published form of this contribution, or allow others to do so, for U.S. Government purposes."}

Full paper for oral presentation and publication at the 1998 ANS Radiation Protection and Shielding Division Topical Conference, Nashville, TN, April 19-23, 1998.

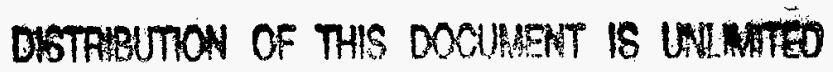

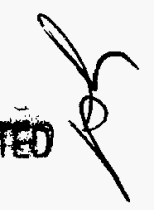

*Research sponsored by the Oak Ridge National Laboratory managed by Lockheed Martin Energy Research Corporation for the U.S. Department of Energy under contract No. DE-AC05-96OR22464. 


\section{DISCLAIMER}

This report was prepared as an account of work sponsored by an agency of the United States Government. Neither the United States Government nor any agency thereof, nor any of their employees, makes any warranty, express or implied, or assumes any legal liability or responsibility for the accuracy, completeness, or usefulness of any information, apparatus, product, or process disclosed, or represents that its use would not infringe privately owned rights. Reference herein to any specific commercial product, process, or service by trade name, trademark, manufacturer, or otherwise does not necessarily constitute or imply its endorsement, recommendation, or favoring by the United States Government or any agency thereof. The views and opinions of authors expressed herein do not necessarily state or reflect those of the United States Government or any agency thereof. 


\title{
Examination of Radioactive Decay Methodology in the HASCAL Code
}

\author{
R. S. Steffler, J. C. Ryman, J. C. Gehin, B. A. Worley
}

\begin{abstract}
The HASCAL 2.0 code provides dose estimates for nuclear, chemical, and biological facility accident and terrorist weapon strike scenarios. In the analysis of accidents involving radioactive material, an approximate method is used to account for decay during transport. Rather than perform the nuclide decay during the atmospheric transport calculation, the decay is performed a priori and a table look-up method is used during the transport of a depositing tracer particle and non-depositing (gaseous) tracer particle. In order to investigate the accuracy of this decay methodology two decay models were created using the ORIGEN2 computer program. The first is a HASCAL-like model that treats decay and growth of all nuclides explicitly over the time interval specified for atmospheric transport, but does not change the relative mix of depositing and non-depositing nuclides due to deposition to the ground, nor does it treat resuspension. The second model explicitly includes resuspension as well as separate decay of the nuclides in the atmosphere and on the ground at each deposition time step. For simplicity, both of these models uses a one-dimensional layer model for the atmospheric transport.

An additional investigation was performed to determine the accuracy of the HASCAL-like model in separately following Cs-137 and I-131.

The results from this study show that the HASCAL decay model compares closely with the more rigorous model with the computed doses are generally within one percent (maximum error of 7 percent) over 48 hours following the release. The models showed no difference for $\mathrm{Cs}-137$ and a maximum error of 2.5 percent for I-131 over the 96 hours following release.
\end{abstract}

\section{INTRODUCTION}

\subsection{BACKGROUND AND OBJECTIVE}

The nuclear facility accident (NFAC) module of the Defense Special Weapons Agency's (DSWA) computer code, Hazard Assessment Consequence Analysis (HASCAL) 2.0, was investigated to determine if it needs enhancements and modifications. The Second-Order Closure, Integrated PUFF (SCIPUFF) module of HASCAL currently uses two groups for radionuclide transport: depositors and non-depositors. This study looks at the addition of two additional groups to the transport methodology for individual analysis. One group would hold only Cs-137; the other, only I-131. This study also examines the accuracy of the radioactive decay and deposition methodology. The current decay methodology in HASCAL performs the decay of all nuclides before the calculation of the atmospheric dispersion and deposition. This calculation is used to produce an interpolation table of doses versus time for all nuclides. Such a table reduces the amount of data that must be tracked during atmospheric transport, thus speeding calculation and lowering the necessary storage requirements. However, as a result of this simplification the relative mix of depositing and non-depositing nuclides due to deposition and the resuspension of radionuclides is not properly accounted for in the decay. A more rigorous model of decay, deposition, and resuspension is compared to a simplified model of HASCAL. The goal of this study is to determine the accuracy of this approximation for each of the doses computed by HASCAL.

Note that the releases that were studied are constant releases of nuclides that correspond to typical pressurized-water reactor fuel (PWR) at time of discharge to the spent fuel pool. In particular, the source terms for all calculations performed in this study is one metric ton of PWR fuel with a burnup of 33,000 MWD/kg-HM.

\section{DESCRIPTION OF HASCAL METHOD OF DECAY AND DEPOSITION}

\subsection{INTRODUCTION}

The NFAC module of the HASCAL program (DSWA, 1997) decays all nuclides in its source term to the desired time after release. The nuclides present are separated by category into a depositor and a non-depositor 
group. A module of the HASCAL program called SCIPUFF (Sykes, 1995) then calculates the transport and deposition of the two categories of nuclides.

The current decay methodology in HASCAL performs the decay of the nuclides before the release calculation to produce an interpolation table of dose factors (dose per total activity) versus time for both the depositing and non-depositing groups. This simplification lowers the number of items that must be tracked during the atmospheric transport calculation, greatly reducing storage and calculation requirements. However, as a result of this simplification the relative mix of depositing and non-depositing nuclides due to deposition and the resuspension of radionuclides is not properly accounted for in the decay

\subsection{DECAY}

The source term in HASCAL is decayed using the solutions to the Bateman equations for solving decay matrices. To approximate the decay methodology that HASCAL uses, this study uses ORIGEN2 (Croff, 1980) to decay one metric ton of spent PWR fuel with a discharge burnup of $33 \mathrm{MWD} / \mathrm{kg}-\mathrm{HM}$. ORIGEN2 is a computcr code developed at Oak Ridge National Laboratory that performs irradiation and decay calculations.

\subsection{DEPOSITION}

The method of deposition within the HASCAL program uses a sophisticated three-dimensional mass transport model. The SCIPUFF code creates three-dimensional concentrations that are dispersed as Gaussian puffs. In connection with this analysis, SCIPUFF also uses turbulent diffusion to take into account atmospheric turbulence, dispersion, and deposition.

In order to analyze other characteristics of the decay and deposition methodology in HASCAL, the method of deposition was simplified to avoid the complicated nature of the SCIPUFF model. For this study, a onedimensional model of deposition was used. The assumption inherent in this simplification is that effects depending upon decay in the simplified model are of the same order of magnitude as in the SCIPUFF threedimensional model.

The deposition rate for a one dimensional deposition model is

$$
\frac{\mathrm{dm}_{\mathrm{d}, \mathrm{i}}^{\mathrm{air}}}{\mathrm{d} t}=-m_{d, i}^{a i r}(t) \cdot\left[\frac{v_{d}}{L_{H}}\right] \text {, }
$$

where

$$
\begin{array}{ll}
m_{d, i}^{\text {air }}(t) & =\text { mass of depositor nuclide, } \mathrm{i}, \text { in the air at time, } \mathrm{t}[\mathrm{kg}], \\
v_{d} & =\text { deposition velocity }[\mathrm{m} / \mathrm{s}], \text { assumed to be } 0.003 \mathrm{~m} / \mathrm{s} \text { for all calculations in this study, } \\
L_{H} & =\text { mixing height }[\mathrm{m}], \text { assumed to be } 300 \mathrm{~m} \text { for all calculations in this study. }
\end{array}
$$

Solving Eq. 1 for the mass of the depositor nuclide, i, in the air at time, t, yields

$$
m_{d, i}^{a i r}(t)=m_{d, i}^{a i r}(0) \cdot e^{-\left(\frac{v_{d}}{L_{H}}\right) \cdot t}
$$

where

$$
m_{d, i}^{a i r}(0) \quad=\text { the initial mass of the depositor nuclide, } i \text {, in the air }[\mathrm{kg}] .
$$

The amount of material deposited, assuming no initial material on the ground, for each depositor nuclide is

$$
m_{d, i}^{g s}(t)=m_{d, i}^{a i r}(0) \cdot\left(1-e^{-\left(\frac{v_{d}}{L_{H}}\right) \cdot t}\right),
$$


where

$$
m_{d, i}^{g s}(t) \quad=\text { mass of depositor nuclide, } \mathrm{i} \text {, on the surface at time, } \mathrm{t}[\mathrm{kg}] .
$$

Non-depositors are considered to be all isotopes of the elements hydrogen, helium, nitrogen, neon, argon, krypton, xenon, and radon. Depositors are the isotopes of all the other elements.

\subsection{HASCAL MODEL}

For this study, a model using the ORIGEN2 code was constructed to imitate the decay and deposition methodologies used in HASCAL. The source term is one metric ton of spent PWR fuel. After the fuel irradiation, the material was decayed for 48 hours in one hour increments. After the decay calculation was performed, the deposition was modeled using Eq. 2. The amount removed was an accumulated activity on the ground from time equal to zero until the specified time after release.

Inhalation doses for each time step were calculated using the activity that had not been deposited. The inhalation doses that were calculated are: Acute Lung 30-day, CEDE (Committed Effective Dose Equivalent) 50-year, Acute Bone 30-day, and Committed Thyroid 50-year. An Effective Immersion dose was derived from the activity suspended in the air. Effective groundshine dose was calculated using the activity that had been deposited for the specified time period. Dose coefficients for this study are the same as those used in HASCAL (DSWA, 1997; US EPA, 1988; US EPA, 1993).

The inhalation doses were calculated using the activity inhaled by a person submerged in the cloud of material and the dose coefficients from HASCAL. The concentration of a non-depositing nuclide, $i$, in the air at time, $t$, is

$$
C_{n d, i}^{a i r}(t)=\frac{1}{3.7 \cdot 10^{10} \cdot A \cdot L_{H}} \cdot \frac{\lambda_{i} \cdot m_{n d, i}^{\text {air }}(t) \cdot N_{A}}{M},
$$

where

$$
\begin{array}{ll}
C_{n d, i}^{\text {air }}(t) & =\text { concentration in air of non-depositor nuclide, } \mathrm{i}\left[\mathrm{Ci} / \mathrm{m}^{3}\right], \\
A & =\text { area, }\left[\mathrm{m}^{2}\right], \\
m_{n d, i}^{\text {air }}(t) & =\text { mass in the air of non-depositor nuclide, } \mathrm{i}[\mathrm{kg}], \\
N_{A} & =\text { Avogadro constant, } \\
\lambda_{i} & =\text { decay constant for nuclide, } \mathrm{i}\left[\mathrm{s}^{-1}\right], \\
M & =\text { molar mass of nuclide, } \mathrm{i}[\mathrm{kg} / \mathrm{mol}] .
\end{array}
$$

Similarly, the concentration of a depositor nuclide, $\mathrm{i}$, in air at time $\mathrm{t}$ is

$$
C_{d, i}^{a i r}(t)=\frac{1}{3.7 \cdot 10^{10} \cdot A \cdot L_{H}} \cdot \frac{\lambda_{i} \cdot m_{d, i}^{a i r}(t) \cdot N_{A}}{M} .
$$

The inhaled activity of nuclide, $i$, is

$$
A_{i n h, i}(t)=\int_{0}^{t} C_{i}^{a i r}\left(t^{\prime}\right) \cdot R_{B}\left(t^{\prime}\right) \cdot d t^{\prime},
$$

where

$$
\begin{array}{ll}
A_{\text {inh,i }}(t) & =\text { activity of nuclide, } \mathrm{i}, \text { inhaled }[\mathrm{Ci}], \\
C_{i}^{a, r}(t) & =\text { concentration in air of nuclide, } \mathrm{i}\left[\mathrm{Ci} / \mathrm{m}^{3}\right], \\
R_{B}(t) & =\text { work exposure breathing rate assumed to be } 3.333 \times 10^{-4}\left[\mathrm{~m}^{3} / \mathrm{s}\right] .
\end{array}
$$


The activity, measured in $\mathbf{C i}$, deposited on the ground for each nuclide is

$$
A_{g s, i}(t)=\frac{1}{3.7 \cdot 10^{-10} \cdot A} \cdot \frac{\lambda_{i} \cdot m_{d, i}^{g s}(t) \cdot N_{A}}{M} .
$$

The doses are obtained by combining the appropriate activity with the dose coefficients used in HASCAL. To calculate Effective Immersion, the activity concentration in air (in $\mathrm{Ci} / \mathrm{m}^{3}$ ) of each nuclide is combined with the dose coefficient in HASCAL for that nuclide.

\section{DESCRIPTION OF ENHANCED DECAY AND DEPOSITION MODEL}

\subsection{INTRODUCTION}

The enhanced decay and deposition (EDD) model was created to test the effects of deposition and resuspension during the decay process on calculated doses. EDD is a more rigorous model of the decay and deposition processes in that all of the nuclides are explicitly tracked using the one-dimensional transport model of Section 2.3, with decay being performed during the transport calculation. Therefore, such effects as resuspension are explicitly treated, unlike that of the HASCAL decay model. This model will allow for a comparison of the two methods of obtaining doses.

\subsection{EDD MODEL}

The source in the EDD model consists of the same one metric ton of spent PWR fuel as for the HASCAL model. The total time for the model nun is 48 hours, divided into time steps of 1 hour. In each time step the airborne fuel is first decayed. Material on the ground, initially assumed to be zero, is decayed at the same time as the airborne fuel material. The depositor components of the airborne fuel material are deposited to the ground using Eq. 3. The non-depositor material formed as daughter products from the decay of material on the ground are added to the airborne material as resuspended material. The doses for the airborne components and the deposited materials are then calculated for that time step as they are in the HASCAL model. The process continues until the final decay time is reached.

\subsection{COMPARISON TO HASCAL MODEL}

The results for the six different doses obtained from the EDD model were compared to the same doses from the HASCAL model. The values computed with the EDD model are the reference values in the comparison. Doses are broken down into the elemental groups that are used by HASCAL which are summarized in Table 1. The differences between the total doses are also given.

\section{EXAMINATION OF SEPARATE GROUPINGS FOR I-131 AND CS-137}

\subsection{INTRODUCTION}

In the current HASCAL program, the ability to track individual nuclides or the doses from individual nuclides is not available. This part of the study examines the possibility of creating separate groups for I-131 and Cs-137, in order to track each nuclide's contribution to the overall dose. The examination is performed using ORIGEN2 to simulate I-13I and Cs-137 in isolation from other nuclides. 


\subsection{THE NUCLIDES}

Iodine-131 is particularly important in dose calculations in that a large fraction of the dose accumulated by the human population after a nuclear power reactor accident is due to I-131. Iodine-131 is easily incorporated into the milk supply of surrounding areas. The isotope tends to deposit on foliage, is then ingested by animals, and is finally excreted through their milk (Kathren, 1984). In humans, iodine concentrates in the thyroid.

Cesium-137 is an alkali metal that exhibits a similar biochemical behavior to potassium. The alkali metals tend to assimilate easily into the surrounding biota, including portions of the food chain (Kathren, 1984). Once in the human body, Cs-137 can be found spread throughout the soft tissue (Kathren, 1984).

\subsection{DEPOSITION}

The methods used for deposition of nuclides in the ORIGEN2 calculations are similar to the method employed in the simplified HASCAL model which was presented in Section 2. The difference between this model and the simplified HASCAL model is that the nuclide dispersion and deposition is performed during the decay calculation (at the end of every two-hour time step) whereas in the simplified HASCAL model the dispersion and deposition is performed after the entire decay calculation.

\subsection{METHOD}

The reference calculation, to which the separate grouping model was compared, is one metric ton of spent PWR fuel. The burn was followed by 96 hours of decay and deposition, performed with ORIGEN2. At the end of each two hour time step, the depositors in the fuel mix were deposited according to Eq. 3, using $\mathrm{v}_{\mathrm{d}}$ equal to 0.003 $\mathrm{m} / \mathrm{s}$ and $L_{H}$ equal to $300 \mathrm{~m}$. The activities of Cs-137 and I-13I that remained suspended in the air were output for comparison.

Separate groupings for iodine and cesium were created in the ORIGEN2 model using the PRO command. This command allowed for separating all iodine and cesium isotopes from all other nuclides found in the irradiated fuel. Immediately following the fuel irradiation all isotopes of iodine and cesium were separated from the rest of the fuel. The iodine and cesium decayed for two hour intervals over a total time of 96 hours. After each interval of two hours, any nuclides other than those of iodine and cesium were removed using the PRO command. Also, at the end of each interval, the isotopes of iodine and cesium were deposited according to Eq. 3. The activities of the various isotopes of iodine and cesium that had not been deposited were used for comparison to the control sample.

\section{RESULTS}

\subsection{COMPARISON OF HASCAL MODEL AND EDD MODEL}

The doses from the HASCAL model and the EDD model were compared for each of the six doses. A plot showing the comparison of the doses is given in Fig. 1. The comparison of the doses for Acute Lung 30-day, CEDE 50-year, Acute Bone 30-day, and Committed Thyroid 50-year show that the percent differences over a 48 hour period do not exceed, either positively or negatively, $0.4 \%$.

The comparison of the Effective Immersion doses differences, presented in Fig. 2., shows an increased percent difference for the alkali metals over the first 30 hours after the release. The peak is approximately a 1.2 percent difference at 8 hours. The total Effective Immersion dose does not vary more than $0.2 \%$ over the first 48 hours.

As shown in Fig. 3., all groups, except the alkali metals, in the Effective Groundshine dose, begin with a 1 percent difference, fading linearly to near zero percent at approximately 5 hours after release. The alkali metals exhibit a large negative percent difference over the first 25 hours after release. The peak is slightly less than $-6.0 \%$ 
at 4 hours after release. The total Effective Groundshine dose peaks at $1 \%$ and decrease to near zero percent at 5 hours.

\subsection{SEPARATE GROUPINGS FOR I-131 AND CS-137}

The activities of I-131 and Cs-137 from two separate models run with ORIGEN2 were compared. Each nuclide was decayed and deposited by both models for 96 hours. The comparison of the activities of I-131 and Cs137 from the two models of groupings are compared in Fig. 4. The activities of Cs-137 show nearly zero differences over the 96 hour period. The activities of I-131 exhibit increasing differences throughout the 96 hours, with the maximum difference approaching $2.5 \%$ at 96 hours.

\section{DISCUSSION}

\subsection{COMPARISON OF HASCAL MODEL AND EDD MODEL}

All the inhalation doses show nearly no difference between the HASCAL and EDD models. Thus, it seems that these four inhalation doses are nearly unaffected by the addition of resuspension and different decay method of the EDD model.

The Effective Immersion dose has a slight increase in the dose from the alkali metals, which includes rubidium. This increase is possibly caused by the increase in $\mathrm{Kr}-90$ in the air due to resuspension after decay of Br-90. Krypton-90 decays to Rb-90, which only affects the Effective Immersion and Effective Groundshine doses. Rubidium-90 decays to $\mathrm{Sr}-90$. The resuspension of $\mathrm{Kr}-90$ leads to more of the $\mathrm{Rb}-90$ decay chain in the air, leading to initially increased Effective Immersion dose from the alkali metals. The total Effective Immersion doses are not significantly different in the two models. The total dose varies by no more than $0.5 \%$.

The Effective Groundshine doses obtained with the two models differ by nearly a percent in the first hour after release. All the groups' doses drop to near zero within 5 hours, but the alkali metals' doses differ by over $6.0 \%$ at 3 and 4 hours, with a non-linear decrease to nearly zero percent difference after 20 hours. As expected, the percent difference is the negative of that in the Effective Immersion. That is, the same nuclide or nuclides that are causing an increase in inhalation doses in a model will be absent from the ground, in similar amounts, causing a lower Effective Groundshine dose for that model. The total doses for the Effective Groundshine doses differ by no more than approximately $1.0 \%$ at any time.

\subsection{SEPARATE GROUPINGS FOR I-131 AND CS-137}

The comparison of the percent differences for I-131 and Cs-137 indicates that the two nuclides may be separated out from the other nuclides with minimal effects on the activities of I-131 and Cs-137. The increasing percent difference with time for I-131 is a result of the separation of Te-131 and Te-131m from I-131. The removal of these parent nuclides of I-131 fully accounts for the percent differences between the two cases.

No calculations were done to determine the effects on the daughter products of I-131 or those of Cs-137. Because of the long half life of Cs-137 and the minimal impact of the removal on the activity of Cs-137, it is believed that the removal will not greatly affect the Cs-137 daughter products' activities. Iodine-131 decays to Xe-131, which is considered a non-depositor. Removal of I-131 from the other nuclides could have an impact on the doses due to Xe-131, even though Xe-131 is a stable nuclide. Although, Xe- $131 \mathrm{~m}$ contributes to the Effective Immersion dose and the Effective Groundshine dose, any removal of I-131 would not affect the four inhalation doses.

\section{CONCLUSIONS}

The doses calculated using the EDD model do not differ greatly from the those of the simplified HASCAL model for the release of nuclides representing PWR fuel at discharge. The total doses from each of the two models are nearly identical for all six doses calculated in this study. The results from this study show that the HASCAL 
decay model compares closely with the more rigorous separate decay of nuclides in the atmosphere and on the ground.

The results from the ORIGEN2 models indicate that using separate groups for I-131 and Cs-137 does not produce significantly different activities from the current model using groups for depositors and non-depositors. Separating I-131 will result in less than a 3\% error in activity for any time less than 96 hours. Additionally, the ORIGEN2 results suggests that separating Cs-137 from other nuclides will result in nearly no error in activity in the first 96 hours after release. These findings indicate that adding separate groups for I-131 and Cs-137 to the transport models will not significantly affect the calculated doses.

\section{ACKNOWLEDGMENTS}

The research was performed under appointment to the Applied Health Physics Fellowship Program administered by Oak Ridge Institute for Science and Education under contract number DE-AC05-76OR00033 between the U.S. Department of Energy and Oak Ridge Associated Universities.

\section{REFERENCES}

Croff, A. G. A User's Manual for the ORIGEN2 Computer Code. ORNL TM-7175. Oak Ridge, TN: Oak Ridge National Laboratory; July 1980.

Defense Special Weapons Agency. HASCAL/SCIPUFF User's Guide. Alexandria, VA: Defense Special Weapons Agency; March 1997.

Kathren, Ronald L. Radioactivity in the Environment: Sources, Distribution, and Surveillance.

Philadelphia, PA: Harwood Academic Publishers; 1984.

Sykes, R. 1., et al. PC-SCIPUFF Version 0.2, Technical Documentation, A.R.A.P. Report No. 712, Titan Corporation; April 1995 DRAFT.

U. S. Environmental Protection Agency. External Exposure to Radionuclides in Air, Water and Soil. Federal Guidance Report No. 12, EPA-402-R-93-081, 1993.

U. S. Environmental Protection Agency. Limiting Values of Radionuclide Intake and Air Concentrations and Dose Conversion Factors for Inhalation, Submersion, and Ingestion. Federal Guidance Report No. 11, EPA520/1-88-0020, 1988.

Table 1. Elements by Group used by HASCAL

\begin{tabular}{ll}
\hline Group & Elements in Group \\
\hline Noble Gases & $\mathrm{Xe}, \mathrm{He}, \mathrm{Ne}, \mathrm{Ar}, \mathrm{Kr}, \mathrm{Rn}, \mathrm{H}, \mathrm{N}$ \\
Alkali Metals & $\mathrm{Cs}, \mathrm{Li}, \mathrm{Na}, \mathrm{K}, \mathrm{Rb}, \mathrm{Fr}, \mathrm{Cu}$ \\
Alkaline Earths & $\mathrm{Ba}, \mathrm{Be}, \mathrm{Mg}, \mathrm{Ca}, \mathrm{Sr}, \mathrm{Ra}, \mathrm{Es}, \mathrm{Fm}$ \\
Halogens & $\mathrm{I}, \mathrm{F}, \mathrm{Cl}, \mathrm{Br}, \mathrm{At}$ \\
Chalcogens & $\mathrm{Te}, \mathrm{O}, \mathrm{S}, \mathrm{Se}, \mathrm{Po}$ \\
Platinoids & $\mathrm{Ru}, \mathrm{Rh}, \mathrm{Pd}, \mathrm{Re}, \mathrm{Os}, \mathrm{Ir}, \mathrm{Pt}, \mathrm{Au}, \mathrm{Ni}$ \\
Early Transition Elements & $\mathrm{Mo}, \mathrm{V}, \mathrm{Cr}, \mathrm{Fe}, \mathrm{Co}, \mathrm{Mn}, \mathrm{Nb}, \mathrm{Tc}, \mathrm{Ta}, \mathrm{W}$ \\
Tetravalents & $\mathrm{Ce}, \mathrm{Ti}, \mathrm{Zr}, \mathrm{Hf}, \mathrm{Th}, \mathrm{Pa}, \mathrm{Np}, \mathrm{Pu}, \mathrm{C}$ \\
Trivalents & $\mathrm{La}, \mathrm{Al}, \mathrm{Sc}, \mathrm{Y}, \mathrm{Ac}, \mathrm{Pr}, \mathrm{Nd}, \mathrm{Pm}, \mathrm{Sm}, \mathrm{Eu}, \mathrm{Gd}, \mathrm{Tb}, \mathrm{Dy}$, \\
& $\mathrm{Ho}, \mathrm{Er}, \mathrm{Tm}, \mathrm{Yb}, \mathrm{Tu}, \mathrm{Am}, \mathrm{Cm}, \mathrm{Bk}, \mathrm{Cf}$ \\
Uranium & $\mathrm{U}$ \\
More Volatile Main Group & $\mathrm{Cd}, \mathrm{Hg}, \mathrm{Zn}, \mathrm{As}, \mathrm{Sb}, \mathrm{Pb}, \mathrm{Tl}, \mathrm{Bi}$ \\
Less Volatile Main Group & $\mathrm{Sn}, \mathrm{Ga}, \mathrm{Ge}, \mathrm{In}, \mathrm{Ag}$ \\
\hline
\end{tabular}




\section{Comparison of Total Doses}

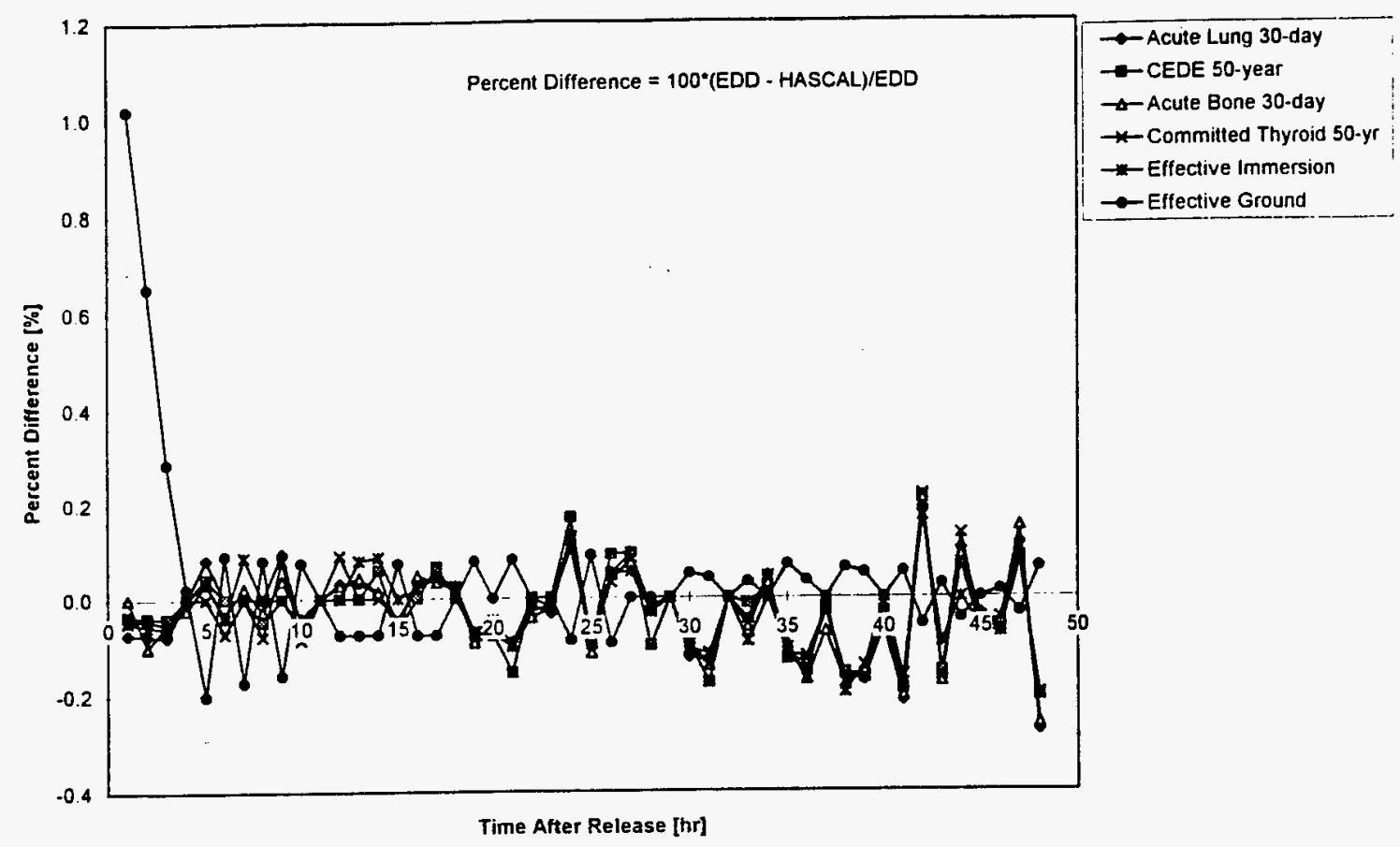

Fig. 1. Comparison of doses computed with HASCAL and EDD models.

\section{Comparison of Effective Immersion Doses by Elemental Groupings}

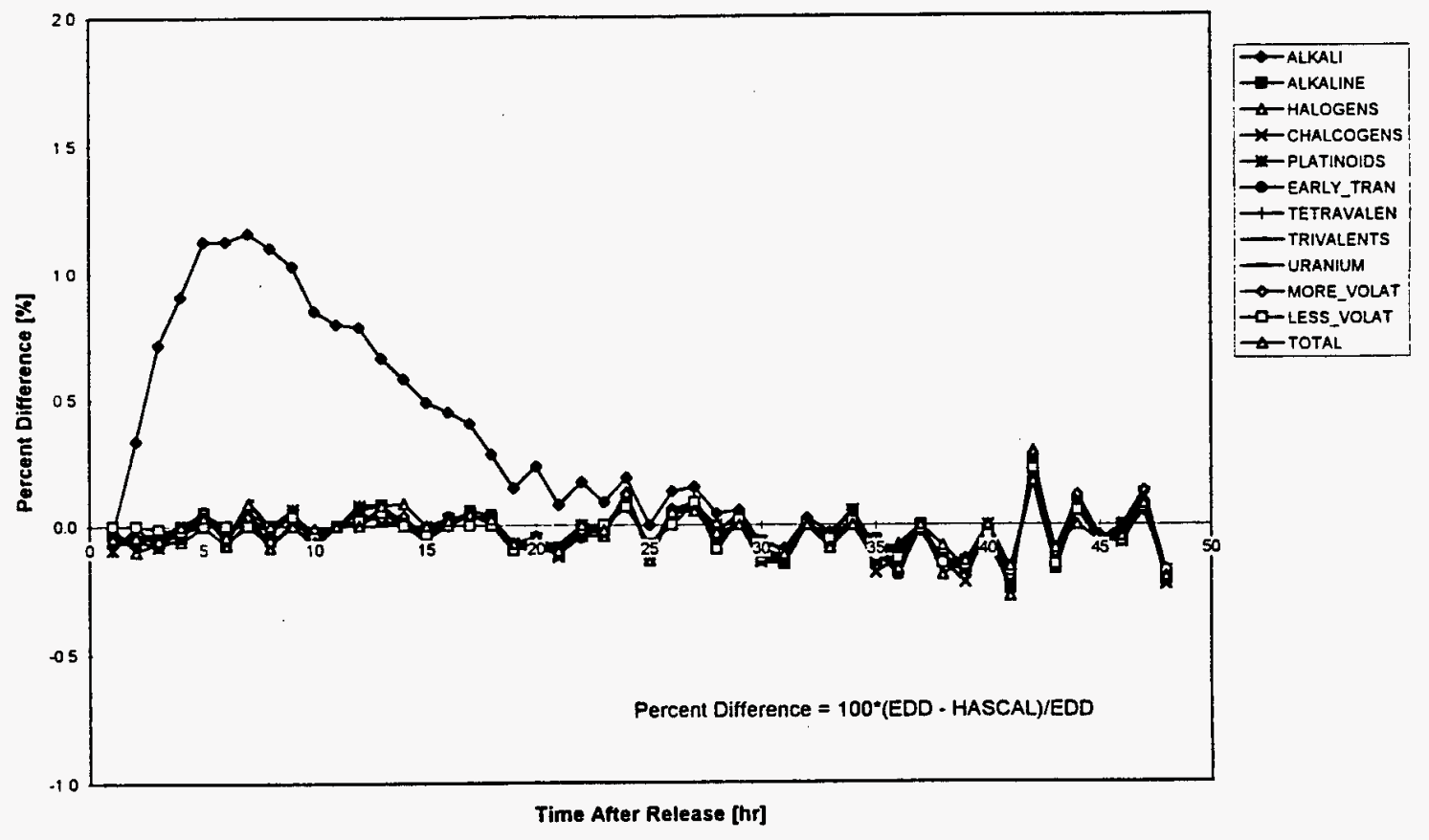

Fig. 2. Comparison of effective immersion dose computed with HASCAL and EDD models. 


\section{Comparison of Effective Groundshine Dose}

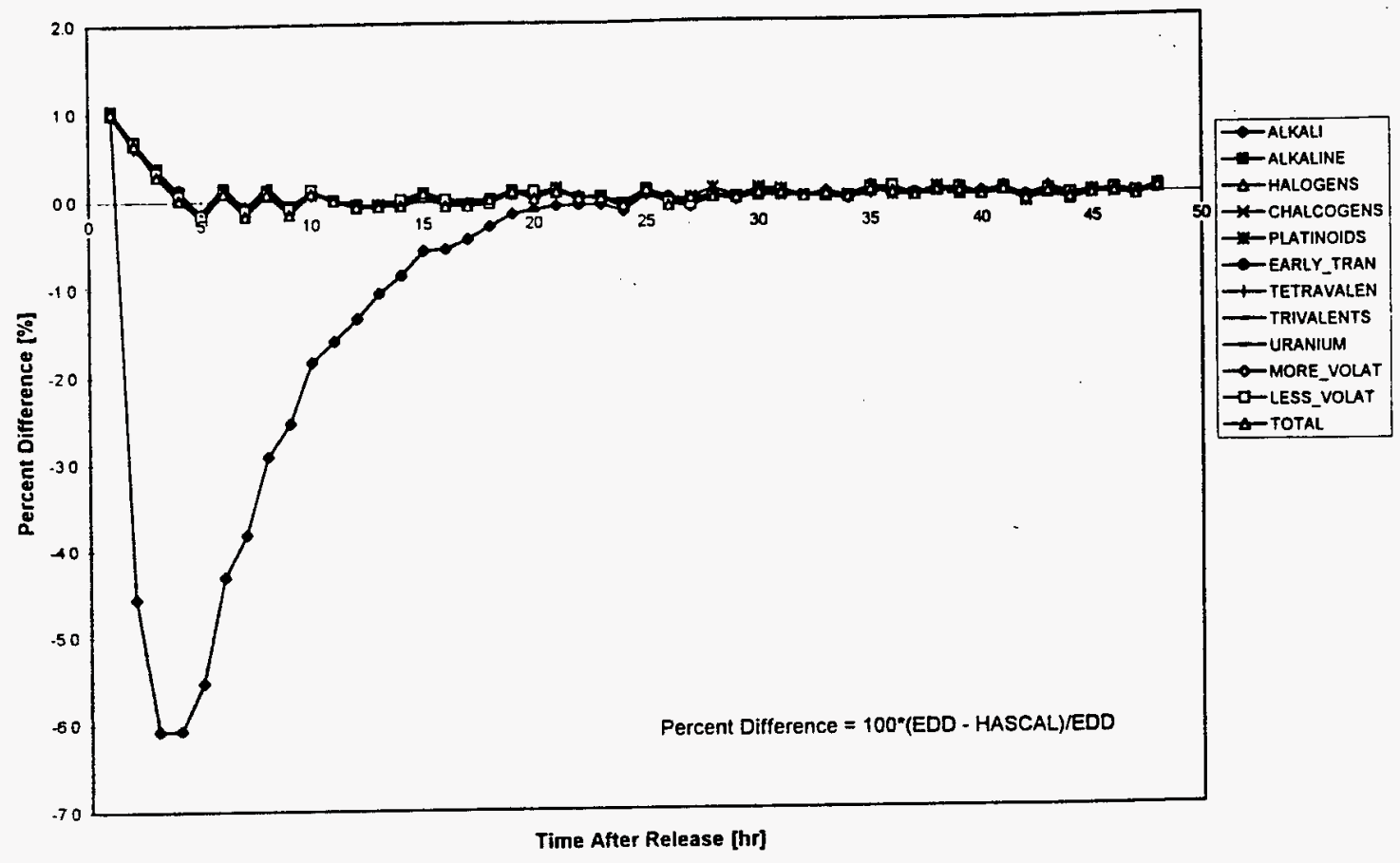

Fig. 3. Comparison of effective ground dose computed with HASCAL and EDD models.

\section{Comparison of l-131 and Cs-137 Activities}

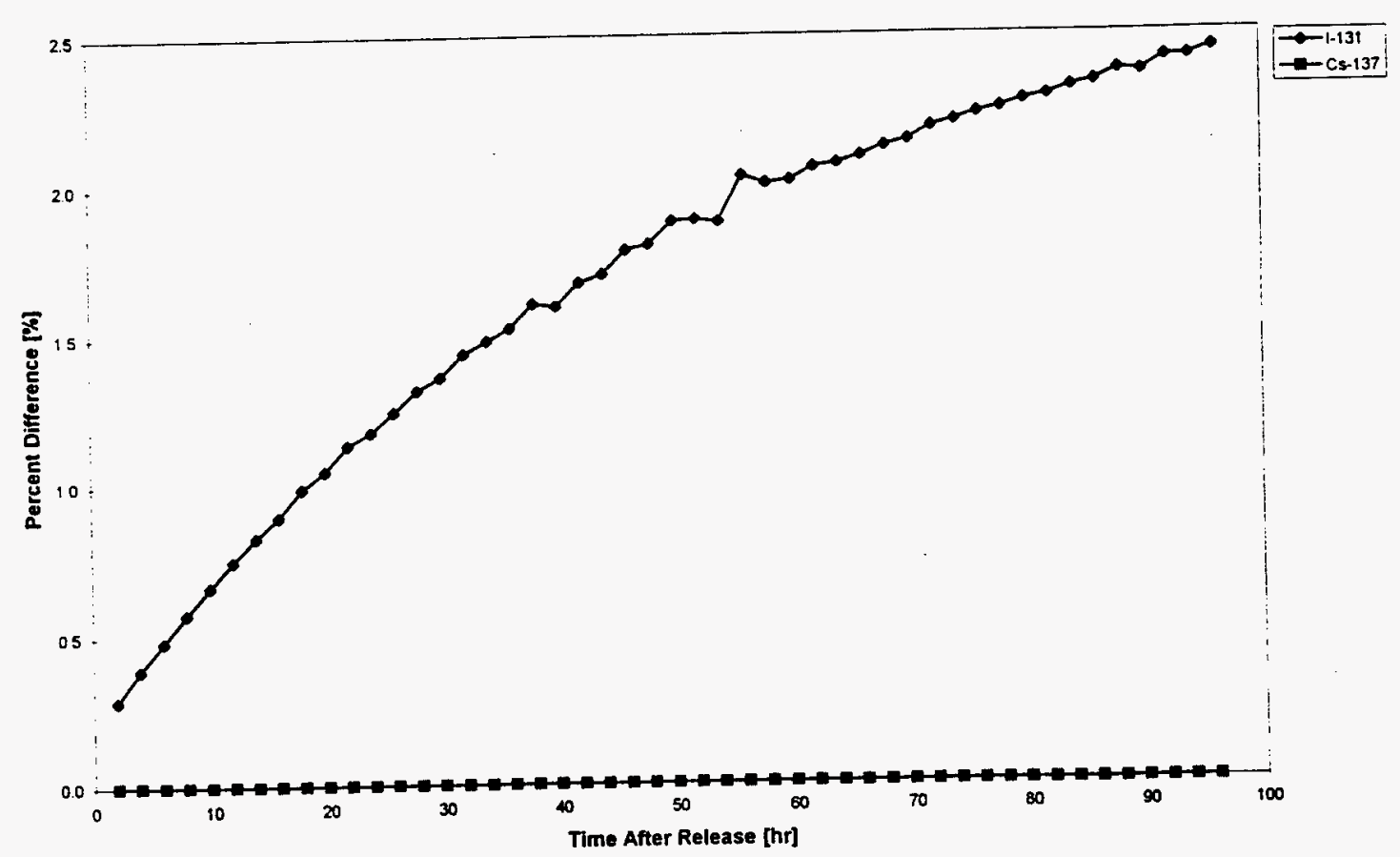

Fig. 4. Comparison of I-131 and Cs-137 activities computed with HASCAL and EDD models. 
M98003173

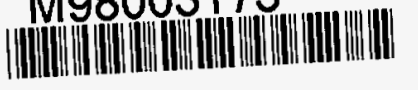

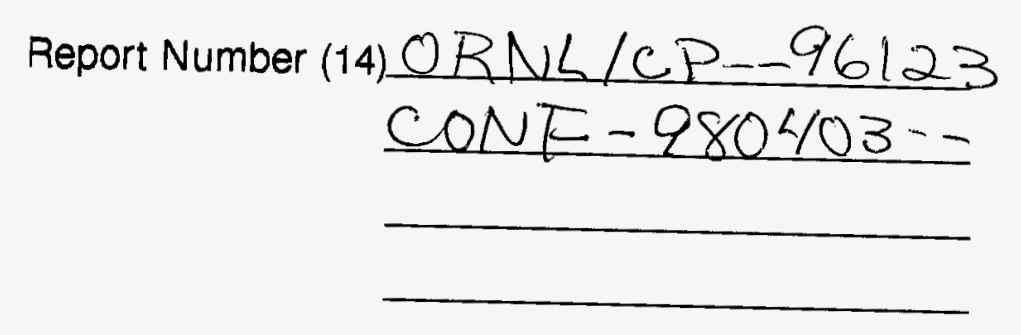

subl. Date (11) $\frac{199801}{\text { sponsor Code (18) }}$

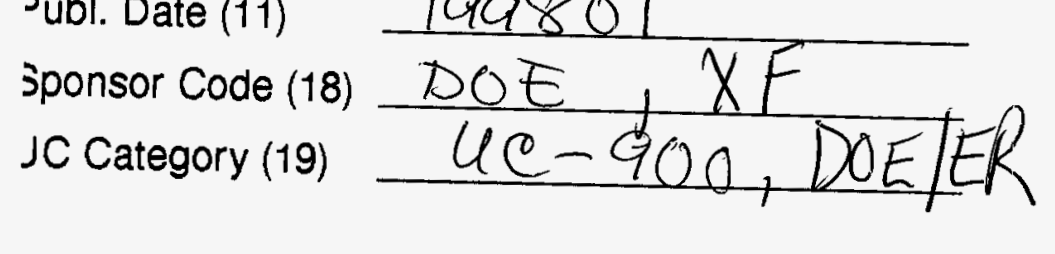

DOE 